\title{
Grounding global environmental assessments through bottom-up futures based on local practices and perspectives
}

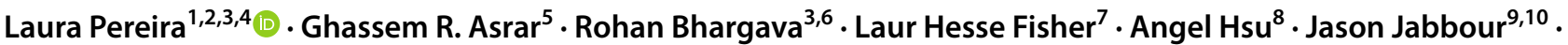 \\ Jeanne $\mathrm{Nel}^{11}$. Odirilwe Selomane ${ }^{1} \cdot$ Nadia Sitas $^{1,12} \cdot$ Christopher Trisos $^{13} \cdot$ James Ward $^{14} \cdot$ Mandy van den Ende $^{3}$. \\ Joost Vervoort ${ }^{3} \cdot$ Amy Weinfurter $^{7}$
}

Received: 27 April 2020 / Accepted: 19 July 2021 / Published online: 13 August 2021

(c) The Author(s) 2021

\begin{abstract}
Future scenarios and pathways of potential development trajectories are powerful tools to assist with decision-making to address many sustainability challenges. Such scenarios play a major role in global environmental assessments (GEAs). Currently, however, scenarios in GEAs are mostly developed at the global level by experts and researchers, and locally imagined, bottom-up scenarios do not play a role in such assessments. In this paper, we argue that addressing future sustainability challenges for achieving more equitable development in GEAs requires a more explicit role for bottom-up inspired futures. To this end, this paper employs an innovative global assessment framework for exploring alternative futures that are grounded in local realities and existing practical actions, and that can be appropriately scaled to the required decisionmaking level. This framework was applied in the context of the UN's Global Environment Outlook 6, a major example of a GEA. We developed novel methods for synthesizing insights from a wide range of local practices and perspectives into global futures. We collected information from crowdsourcing platforms, outcomes of participatory workshops in different regions of the world, and an assessment of reported regional outlooks. We analysed these according to a framework also used by an integrated assessment model in the same GEA. We conclude that bottom-up approaches to identify and assess transformative solutions that envision future pathways towards greater sustainability significantly strengthen current GEA scenario-development approaches. They provide decision makers with required actionable information based on tangible synergistic solutions that have been tested on the ground. This work has revealed that there are significant opportunities for the integration of bottom-up knowledge and insights into GEAs, to make such assessments more salient and valuable to decision makers.
\end{abstract}

Keywords Futures thinking $\cdot$ Global environmental assessments $\cdot$ Innovation $\cdot$ Participatory processes $\cdot$ Scenarios . Sustainable development goals $\cdot$ Transformations

\section{Introduction}

The rapid pace and scale of societal and environmental changes in the anthropocene necessitate important changes in how integrated scientific assessments are carried out to account for such changes from local to regional and global levels. Contemporary global environmental assessments are shifting focus from only synthesizing the current state

Handled by Shizuka Hashimoto, University of Tokyo, Japan.

Laura Pereira

pereira.laura18@gmail.com

Extended author information available on the last page of the article of knowledge towards understanding transformations and interventions needed to mitigate and manage environmental risks (Kowarsch et al. 2017; Jabbour and Flachsland 2017; Castree et al. 2020). This shift in intention and direction is especially relevant in the context of global agendas that require going beyond the current solution space, however, such consideration is also warranted for local and regional levels.

Global environmental assessments (GEAs) distil, synthesize and interpret existing information in ways that intend to be relevant to decision makers. They can help governments to achieve consensus when negotiating complex international agreements (Jabbour and Flachsland 2017). However, GEAs struggle to integrate dynamics at 
local, regional and national to global scales (Bennett et al. 2003) because they rely primarily on global-scale quantitative scenarios (Van Vuuren et al. 2012). These globalscale quantitative scenarios, usually developed using integrated assessment models (IAMs) (Van Vuuren et al. 2012; Calvin et al. 2019), are limited by the extent they can include novelty into their analysis. IAMs also cannot simulate decisions that engage multiple jurisdictional levels, diverse actors, and emerging trends from sub-global scales. As a result, they are not, by themselves, immediately useful to national and sub-national decision making (Biggs et al. 2015).

This paper investigates how analyses based on diverse local practices and perspectives can make a valuable contribution to global environmental assessments. To do so, we describe the development of aggregate insights from large sets of local participatory processes and local practices. We identify locally sourced, bottom-up examples of potential futures that can engage with disruptive change, innovation and transformation. We also consider changes in governance, emphasising the future roles of diverse societal actors. The examples are synthesized in a manner that is uniquely valuable for GEAs, with the results being equally beneficial to local and regional decision makers. The process documented here was used for the Sixth Global Environment Outlook (GEO-6) report (Pereira et al. 2019).

\section{Integrating bottom-up scenarios into global environmental assessments}

The models used in developing GEAs are useful for exploring plausible future behaviour of a global system of interconnected social, environmental and economic elements. This helps to assess broad-scale futures beyond individual contexts. However, future pathways and scenarios often exhibit tensions and alternative options at various scales. For example, global recommendations for healthy diets (e.g. Willett et al. 2019) may not align with regional suitability for recommended crops (Neumann et al. 2010, Chapman et al. 2020). Similarly, global level recommendations for reducing meat consumption, urban/rural linkages, markets and globalisation may not align with regional or national aspirations, which may show preference for agroecology instead of sustainable intensification of production, or argue for localised rather than global food supply chains (Aguiar et al. 2020). GEAs have typically used scenarios and pathways from global perspectives (IPBES 2016), ignoring these local, national and regional considerations. Moreover, global scenarios are usually based on integration of global data and models to project plausible future pathways and outcomes.
The range of explorable futures in GEAs is thus constrained by the mathematical architecture of the model, and there are limits to the complexity and diversity of elements that can be practically simulated and reliably calibrated to available data, especially at local and national levels. To address this, much research has emphasized the downscaling of global scenarios for use at local levels (Zurek and Henrichs 2007; Mason-D'Croz et al. 2016; Palazzo et al. 2017). By contrast, relatively little research has been done on methods that upscale local scenarios, practices and perspectives for use in pathways, syntheses and scenarios at the global level (Pereira et al 2021). This is mainly because tremendous diversity exists across different localities and regions (Aguiar et al. 2020, Chen et al. 2020), and the pace and extent of change at these scales can be highly unpredictable. In short, there is a gap in research on creating global futures through aggregating or synthesizing local scenarios.

As such, most global approaches to scenario development (including those based on IAMs) cannot engage effectively with (1) the roles and behaviour of specific actors and the multi-level policy and practice mechanisms that support transformation, (2) disruptive technologies and processes, and (3) geographic disaggregation to appropriate decision-making levels. Participatory, local approaches can use local narratives and perspectives to offer complementary insights to the GEA process. They can help imagine how local actors might behave in the future; they can consider disruptive change, and they can develop future pathways that are contextualized and practical (Pereira et al. 2021). Additionally, pathways based in local knowledge and practices can be based on existing and potentially transformative initiatives as a starting point (Pereira et al. 2018). This paper leverages this complementarity.

This paper responds to the need for developing a bottomup aggregation and synthesis approach for creating futures based on local practices and perspectives in GEAs. We develop a framework for doing this in the GEO-6 assessment by drawing on an important precursor project. In December 2014, the UN Framework Convention on Climate Change (UNFCCC) launched the Global Climate Action portal to track the diversity of bottom-up actors and their commitments and pledges to climate mitigation, adaptation, financing, capacity-building and other actions in addressing climate change. The portal is evolving towards a consistent methodology to account for quantifying bottom-up actor contributions in global climate mitigation scenarios (Hsu et al. 2019; Kuramochi et al. 2020). It has a three-fold aim to (1) aggregate local climate efforts and their impact on existing climate scenarios to allow for more accurate appraisal of existing emissions pathways and gaps, (2) understand the mitigation contributions of local efforts and provide 
examples that may prompt governments to better support these activities and (3) incorporate local initiatives that are critical to advancing lower carbon trajectories, but are difficult to quantify into global climate scenarios (Chan et al. 2016). We view this kind of cross-scale approach, pioneered in the climate sphere, as highly applicable to environmental sustainability more broadly and draw on it as an example of how to aggregate or upscale bottom-up scenarios. Furthermore, there is growing evidence for the use of bottomup approaches in global assessments as they offer a context for analysing transformative change by documenting actual interventions that are taking place across different scales and levels (UNEP 2019; IPBES 2019; Hsu et al. 2019).

\section{Transformative interventions and sustainability transformations}

There are a growing number of initiatives aimed at identifying local practices and perspectives with the potential to contribute to transformative futures. Some rely on participants submitting their initiatives and activities either through workshops (e.g. The Seeds of Good Anthropocenes (Bennett et al. 2016), or online platforms, e.g. the Climate CoLab (Malone et al. 2017). Some are sector specific, focusing on issues such as sustainable land management (e.g. world overview of conservation approaches and technologies (WOCAT) or climate (e.g. the senses toolkit on climate scenarios https://climatescenarios.org/). Other initiatives are facilitated at regional level, focusing on smallscale social innovations (e.g. transactional environmental support system see Kenward et al. 2013), food sustainability (e.g. TRANSMANGO see Hebinck et al. 2018), and local and regional transitions for a sustainable, low-carbon future $\left(\right.$ PATHWAYS $^{1}$ ), including many funded at the European level through the Horizon 2020 scheme.

Existing literature on sustainability transformations provides a useful framework to understand the governance conditions needed to transform unsustainable systems and scale the innovations identified by the workshop on seeds and Climate CoLab portal (see Kivimaa and Kern 2016 and further details in Sect. 2 below). Sustainability transformations are often multi-phased, with periods related to a problematic status quo, a preparation phase in which innovations begin to develop, a navigation/acceleration phase in which innovations grow and become part of the new system, and an institutionalization phase in which a more desirable system is made sustainable in the long term (Olsson et al. 2006; Moore et al. 2014). For transformations to occur successfully, each of these phases requires governance conditions that are strongly enabling. These enabling conditions include both supporting conditions for scaling innovations appropriately and disrupting conditions for the weakening of existing, problematic structures.

There are challenges associated with aggregating the information captured in these diverse initiatives into bottom-up syntheses, largely due to the plethora of bottom-up knowledge that can be gathered. However, such aggregation if done in a way that allows for the diversity of pathways options to remain clear whilst still providing a coherent message, presents opportunities for collectively informing effective for policy and decision-making, especially at local and national levels. In particular, it allows alignment with higher-level global pathways and policies, e.g. by promoting coherence, consistency, and compatibility (Zurek and Henrichs 2007). Recent sustainability assessments have, therefore, shown an appetite for combining complementary features of bottom-up and top-down scenarios and pathways (Rosa et al. 2017; IPBES 2019; UNEP 2019). Headway is also being made in the field of multi-level governance, especially around climate (see Hölscher and Frantzeskaki 2020). This is an emerging approach, still with many challenges, but there is high demand for such sustainable development scenarios and pathways.

\section{Methodological rationale and approach}

We collated local to regional measures for shifting to more sustainable futures from two types of sources described below: initiatives of locally sourced practices and perspectives, and sub-global regional assessments of GEO-6. We coded each measure according to a measure typology aligned to the IAM analysis for GEO-6, and analysed the underpinning enabling conditions for change.

\section{Gathering and coding local practices and perspectives}

We used two distinct participatory methodologies from local practices and future perspectives on tangible system transformations. These two processes were designed to generate local data on stakeholders' perspectives. The first is a 'Seeds' approach (Bennett et al 2016) and the second is based on the Climate colab platform (Malone et al 2017). Appendix 1 provides a description of the Seeds and Co-lab proposals that were used.

\footnotetext{
${ }^{1}$ https://www.pathways-project.eu/home.
} 


\section{Seeds}

The first participatory process was a series of four workshops held in Bangkok, Guangzhou, Nairobi and Singapore, where local stakeholders were invited to envision specific local transformation pathways. Participants were asked to propose seeds, which are examples of existing, but not yet dominant social initiatives, new technologies, economic tools or social-ecological projects, or organizations, movements or new ways of acting that appear to be making a substantial contribution towards creating a future that is just, prosperous and sustainable (Bennett et al. 2016). They were subsequently asked to build proposals for how to achieve as many SDGs as possible by combining different seeds with one another and exploring how they could interact (UNEP 2017a, 2017b, 2017c, 2018). The four workshops led to 156 seeds and 24 proposals for specific system transformations.

\section{Co-lab}

The second participatory process was an online contest held through the Climate CoLab platform, an online contest platform and community run by the Massachusetts Institute of Technology (MIT). The contest asked participants to combine proposals previously collected by the Climate CoLab platform and to build creative combinations of actions that can achieve climate and sustainable development goals. Proposals' authors worked with each other and with over 800 experts, using the CoLab platform, on climate change and related topics, to create, analyse and select detailed proposals for what to do about different aspects of the climate change problem. The contest was promoted through a wide range of networks, including through UN Environment Programme (UNEP), MIT and other organizational partners worldwide. The Climate CoLab contest resulted in 73 proposals by 112 proposal authors; featured 188 proposal comments; and saw 3064 votes being cast. The judges selected 12 final proposals plus a judges' choice winner from both processes. The public was also invited to vote for the proposal most deserving of a popular choice award out of the 12 .

\section{Coding proposed measures}

To synthesize local practices and perspectives into higherlevel futures, we aligned the coding of the proposed local practices and regional measures to a pre-defined measures typology that was applied in the global IAM framework to model the GEO-6 alternative scenarios (Van Vuuren et al 2019). The typology identifies 33 measures which are grouped hierarchically into four "clusters": energy, climate and air, agriculture, food, land and biodiversity, human wellbeing, and freshwater and oceans (Table 1). As an iterative process, The Seeds and CoLab proposals were coded based on the availability and quality of the data submitted, so not all the results could be coded on all dimensions. The initiatives were coded according to our typology measures as well as SDGs that they addressed, to derive an SDG-measures pairing matrix. Coding was done by a single person to ensure consistency. A proposed initiative could be assigned to many measures such that a single proposal could have multiple intervention types across multiple clusters. The initiatives were assessed and coded according to a matrix of measures and SDGs pairings to derive a heat map. Where initiatives did not fit into these existing clusters of measures, they were added into an 'Additional regional \& bottom-up interventions' category (See Results and Fig. 4).

\section{Gathering and coding regional assessments}

Six GEO regional assessments had been completed in 2016 under UNEP sponsorship: for Africa, Asia and the Pacific, Europe, Latin America and the Caribbean, North America and West Asia (UNEP 2016a, 2016b, 2016c, 2016e, 2016d, 2016f). Each regional assessment highlights region-specific environmental challenges, priorities and the responses, providing important insights on the emphasis that specific regions give to different measures. Solutions or recommendations proposed by the regional assessments are intermediate and potential bridges between global assessments and local practices. Taken together, these solutions provide a set of overarching regional measures for building sustainable futures at a global level. Proposed solutions and recommendations from the Outlooks chapter of each regional assessment were extracted. These were coded as specified in 2.2, where a single proposed solution or recommendation by a regional assessment could be assigned to many measures. By aligning with the global IAM typology, we were thus able to compare similarities between measures recommended at global and regional level, and identify regional measures that constituted gaps in the global coding typology.

\section{Analysis of interventions in light of enabling conditions for change}

The above coding allowed for an understanding of what clusters were being addressed by solutions, but not of the theory of change behind each solution. Seeds and proposals were, therefore, also analyzed under the framework of enabling and disruptive conditions (Kivimaa and Kern 2016). This framework draws on the Schumpeterian notion of 'creative destruction' whereby the authors argue that policy mixes for a transition need to aim at both 'creating the new' whilst 'destabilising the old' (Kivimaa and Kern 2016 205). As such, the framework expands on the innovation for 
Table 1 Coding measures by cluster based on van Vuuren et al 2019

\begin{tabular}{|c|c|}
\hline Cluster & Measure category \\
\hline Energy, air and climate & $\begin{array}{l}\text { Energy access } \\
\text { Behavioural change (transport and } \\
\text { households) } \\
\text { End-use electrification } \\
\text { Low/zero-emission technologies (non- } \\
\text { biomass) } \\
\text { Bioenergy (with and without CCS) } \\
\text { Improve energy efficiency } \\
\text { Negative emission technologies } \\
\text { Air pollution control } \\
\text { Non-CO2 emission reduction }\end{array}$ \\
\hline $\begin{array}{l}\text { Agriculture, food, land and } \\
\text { biodiversity }\end{array}$ & $\begin{array}{l}\text { Reduce food waste } \\
\text { Yield improvement } \\
\text { Nutrition management } \\
\text { Food access } \\
\text { Diet change } \\
\text { Manage soil carbon loss } \\
\text { Minimize land damage } \\
\text { Land ownership } \\
\text { Protection of terrestrial ecosystems } \\
\text { Land-use planning } \\
\text { Forest management }\end{array}$ \\
\hline Freshwater and oceans & $\begin{array}{l}\text { Improve water-use efficiency } \\
\text { Blue carbon } \\
\text { Water, sanitation and hygiene (WASH) } \\
\text { Wastewater treatment } \\
\text { Water quality standards } \\
\text { Desalination } \\
\text { Integrated water resource management } \\
\text { Sustainable fisheries } \\
\text { Ocean regulation } \\
\text { Protection of marine ecosystems }\end{array}$ \\
\hline Human wellbeing & $\begin{array}{l}\text { Poverty alleviation } \\
\text { Child/maternal healthcare } \\
\text { Education }\end{array}$ \\
\hline
\end{tabular}

sustainability transitions literature by arguing that what is important is not only the creation of novelty (enabling innovations), but also the destruction of problematic incumbents (disruptive conditions). This argument aligns well with the transformations literature, such as the Three Horizons heuristic, that argues that there is a need for both growing the alternative 'new' system whilst at the same time breaking down the current dominant system (Sharpe et al 2016). This analytical framework allowed for an understanding of the transformation mechanisms at play in the proposed measures, such as the enabling of experimentation and mobilization of resources, as well as the disruption of incumbent power structures and actors.

\section{Results}

\section{Translating local practices and perspectives into additional synthesized measures}

A substantial portion of solutions did not fit neatly into the four pre-defined categories of measures that had been used in the GEO-6 IAM analysis (see van Vuuren et al 2019), and so a fifth cluster of measure categories ("Additional regional and bottom-up interventions") was created based on the solutions found in the bottom-up analysis (see "Additional regional and bottom-up interventions" in Figs. 1, 2, 3). These will be further discussed in Sect. 3.5, but a key result of this was that nine new measures were developed and coded as part of the analysis:

- Monitoring and reporting: innovations to improve the monitoring and reporting of environmental conditions, including citizen science initiatives.

- Circular economy: innovations that involve the increased efficiency of resource use, specifically through new business models that better engage with the issue of waste products of other production processes (see Ghisellini et al. 2016).

- Sharing economy: innovations related to the peer-to-peer sharing of goods and services, primarily through information and communications technology (ICT) platforms (see Hamari et al. 2016).

- Plastic and solid waste reduction: innovations that help to reduce plastic and solid waste.

- Awareness and skills building: education related to sustainability and environmental issues to improve public awareness and build relevant skills.

- Gender equality: solutions that promote the fair treatment of all genders, including female empowerment and considerations of gender equity.

- Smart cities for sustainability: smart cities use modern digital technologies, such as apps for mobile phones, to engage and connect citizens in addressing their key sustainability challenges, such as city transportation, consumption patterns, energy, nutrition, water and waste.

- Ecosystem restoration: the process of assisting the recovery of an ecosystem that has been degraded, damaged or destroyed. Although this category would fit well under the agriculture, food, land and biodiversity cluster, it is considered as a separate category here due to the empha- 
Fig. 1 Heat map of workshop seeds, showing pairings of specific measures and SDGs. Numbers indicate the count of proposals coded with the specific pairing of intervention (row) and SDG (column). 'Additional regional and bottom-up interventions' is described more in Sect. 3.3

\begin{tabular}{|c|c|c|c|c|c|c|c|c|c|c|c|c|c|c|c|c|c|}
\hline Cluster & 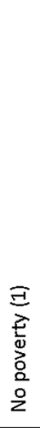 & 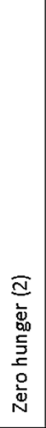 & 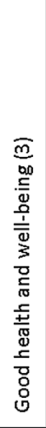 & 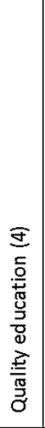 & $\begin{array}{l}\frac{\pi}{2} \\
\frac{3}{0} \\
\frac{0}{0} \\
\overline{0} \\
\frac{0}{0} \\
\frac{0}{0} \\
0 \\
0\end{array}$ & 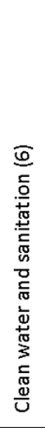 & 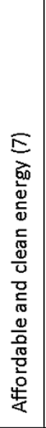 & 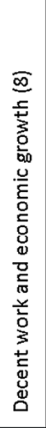 & 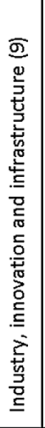 & 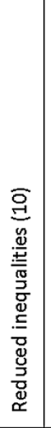 & 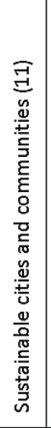 & 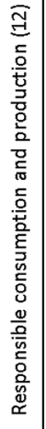 & 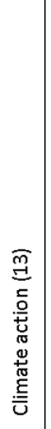 & 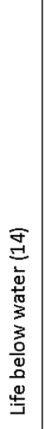 & 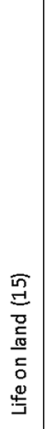 & 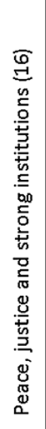 & 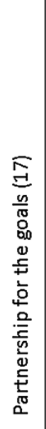 \\
\hline Energy, Air \& Climate & 3 & 2 & 14 & 3 & 0 & 6 & 44 & 19 & 26 & 3 & 31 & 17 & 38 & 2 & 2 & 1 & 4 \\
\hline $\begin{array}{l}\text { Agriculture, Food, Land \& } \\
\text { Biodiversity }\end{array}$ & 11 & 17 & 15 & 14 & 2 & 9 & 6 & 10 & 7 & 1 & 14 & 14 & 14 & 5 & 20 & 0 & 6 \\
\hline Human Wellbeing & 0 & 2 & 4 & 4 & 1 & t & 3 & 7 & 3 & 6 & 4 & 3 & 2 & 0 & 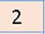 & 2 & 3 \\
\hline Freshwater \& Oceans & 0 & 2 & 4 & 0 & 1 & 14 & 2 & 0 & 4 & 1 & 6 & 3 & 2 & 4 & 3 & 0 & 0 \\
\hline $\begin{array}{l}\text { Additional regional \& bottom-up } \\
\text { interventions }\end{array}$ & 12 & 10 & 26 & 16 & 7 & 15 & 11 & 15 & 19 & 10 & 42 & 57 & 28 & 23 & 22 & 5 & 13 \\
\hline
\end{tabular}

sis on this intervention in the reports. In future assessments, it could be adapted to refer to nature-based solutions, encapsulating those relevant innovations that draw on indigenous knowledge and ecological infrastructure.

- Effective governance: solutions to improve regional cooperation, and harmonization across scales, including to improve the management of interlinkages and tele-coupling between systems to reduce interregional inequalities.

Due to the limits on workshop geography and CoLab submissions (see Appendix 1), the participatory analysis is not representative of all on-the-ground solutions globally. However, it does provide an indication of how this complementarity of online and in-person participatory processes could be more broadly implemented in future environmental assessments.

\section{Findings from participatory workshops}

The participatory Seeds workshops and Climate CoLab crowdsourcing highlighted the diversity of solutions found globally. These initiatives were identified as concrete examples of typical solutions in each of the measure categories used by the IAM analysis (see van Vuuren et al. 2019). They also challenged some of the assumptions on how change happens within top-down models by providing alternative mechanisms for achieving impact, and highlighted the interrelated trends of SDGs, their potential synergies, and the role of diverse actors in achieving the 2030 Agenda. Most of the suggested solutions with transformative potential to enhance human wellbeing or promote environmental conservation were focused on interventions and initiatives that could be implemented in the global South, with a focus on Asia and Africa (Appendix 1). Few proposals focused on interventions that could address the cause of some of the drivers of change stemming from the global North (e.g. solutions for curbing high GHG emitting nations, or unsustainable consumption practices) highlighting an imbalance in terms of where the burden for implementing change is suggested to happen.

The analysis of the Seeds contributed during the GEO-6 participatory workshops showed strong representation of the energy, climate and air cluster, particularly linked to SDGs 7, 11 and 13. Specific interventions within the cluster are detailed in Fig. 1, with popular interventions related to low/zero emissions, behaviour change, energy efficiency and (to a lesser degree) energy access (For a more detailed heatmap for individual measure, see Appendix 2, Fig. 1). The Seeds showed strong representation in the fifth "Additional" cluster (i.e. measure not identified in the top-down IAM). The most prominent of these measures included: awareness and skills building, monitoring and reporting, plastics and consumer waste reduction, and circular economy, with the strongest links to SDGs 11 and 12, and slightly less strong links to SDGs 3 and 13 (Fig. 1). There was modest interest in the agriculture, food, land and biodiversity cluster, with the strongest interventions relating to diet change and protection of terrestrial ecosystems.

The Climate CoLab proposals were quite different from the Seed groupings from the GEO-6 participatory workshops. In the Climate CoLab proposals, the Agriculture, Food, Land and Biodiversity cluster was much more prominent (Fig. 2), with many proposals targeting food access and minimizing land damage (For a more detailed heatmap by individual measure, see Appendix 2, Fig. 2). The proposals also focused heavily on poverty alleviation. SDGs 1, 2, 3 and 13 emerge as strongly linked across many proposals (Fig. 2). Comparatively, few Climate 
Fig. 2 Heat map of Climate CoLab proposals showing pairings of measures and SDGs. Numbers indicate the count of proposals coded with the (row) and SDG (column) specific pairing of intervention

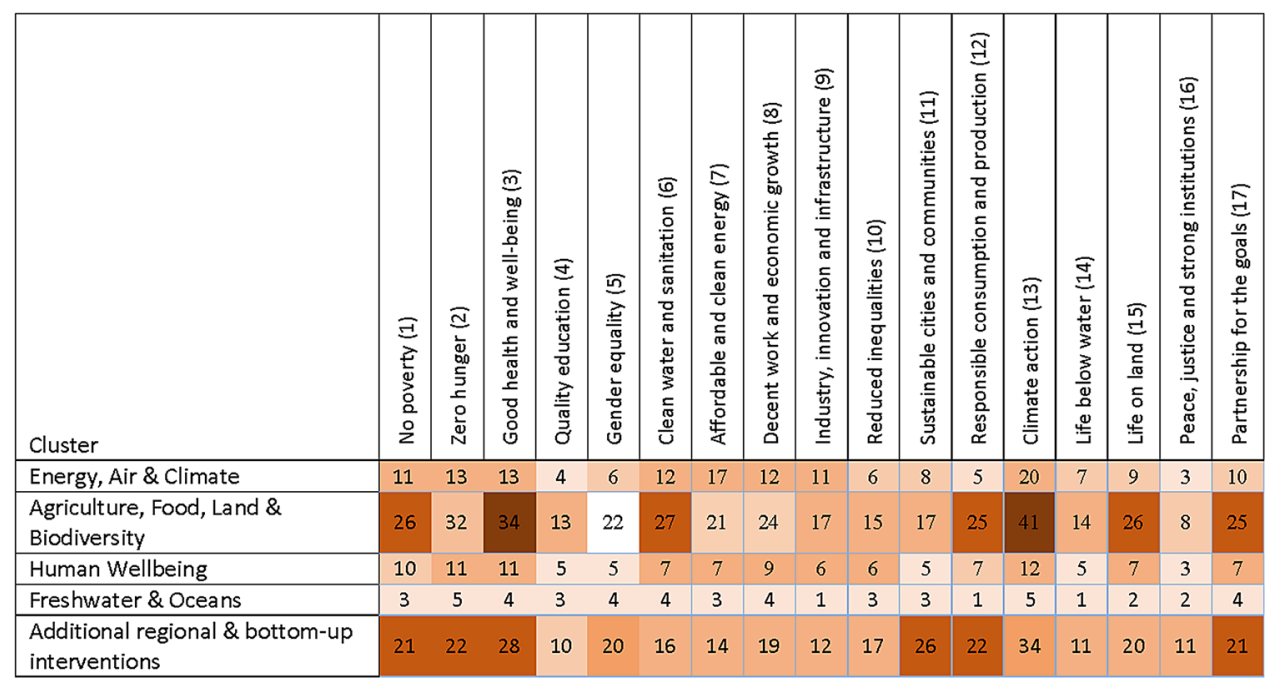

\section{Elaboration on additional measures}

climate and air despite strong representation of SDG 13 (climate action). Gender equality emerged as a strong intervention in Climate CoLab proposals compared with the Seeds, but it was not strongly related to any other SDG. Awareness and skills building in the "Additional" cluster, was strongly represented in both the seeds and Climate CoLab proposals. Neither the Seeds nor the CoLab proposals produced any substantial focus on the merged cluster for freshwater and oceans, although this gap is partially addressed in the analysis of the regional assessments.

\section{Regional assessments}

The most frequently occurring interventions in the GEO regional assessments were low/zero-emission technologies, the protection of terrestrial biodiversity, effective governance, skills and awareness building, and monitoring and reporting (Fig. 3 For a more detailed heatmap by individual measure, see Appendix 2, Fig. 3). They highlighted roughly similar proportions of interventions across regions in the energy, climate and air cluster and in the agriculture, food, land and biodiversity cluster. The interventions in the combined cluster for fresh water and oceans shows only slightly less prevalence (Fig. 3). There was a marked absence of interventions that directly addressed the human well-being cluster, especially related to poverty alleviation (unlike the Climate CoLab proposals in which this cluster was strongly emphasized). There was also evidence of gaps across the regions with reference to a sharing economy and gender equality.
As mentioned above, nine additional measures (included as the "Additional" cluster) were identified from the participatory GEO-6 processes and the review of the Regional Assessments, which had not been included in the IAM analysis (van Vuuren et al 2019). For Seeds and CoLab proposals, the measures that were coded across both "additional" and at least one of the four main clusters, some preliminary patterns emerged, although the sample sizes were small. For Seeds, the most common cluster to be paired with "additional" measures was energy, climate and air, with Seeds linking this cluster to monitoring and reporting, smart cities, and awareness and skills building (Fig. 4). Gender equality appeared in only two Seeds and neither of these was linked to any of the four main clusters. In contrast, in the Climate CoLab proposals, gender equality, and awareness and skills

\begin{tabular}{|c|c|c|c|c|c|c|}
\hline Cluster & 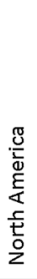 & 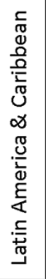 & $\frac{\mathbb{S}}{\stackrel{4}{4}}$ & 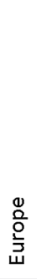 & 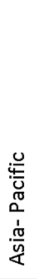 & $\begin{array}{l}\frac{\pi}{y} \\
\frac{1}{y} \\
3 \\
3\end{array}$ \\
\hline Energy, Air \& Climate & 4 & 2 & 4 & 7 & 2 & 2 \\
\hline Agriculture, Food, Land \& Biodiversity & 5 & 4 & 8 & 5 & 0 & 3 \\
\hline Freshwater \& Oceans & 4 & 0 & 5 & 0 & 4 & 5 \\
\hline Human Wellbeing & 0 & 1 & 0 & 0 & 1 & 0 \\
\hline Additional regional \& bottom-up interventions & 6 & 3 & 3 & 5 & 6 & 6 \\
\hline
\end{tabular}

Fig. 3 A heatmap of interventions highlighted by the outlook chapters of the GEO Regional Assessments. The darker the block, the higher the number of those group of measures highlighted by the associated regional assessment; white indicates absence of the measure 
Fig. 4 Count of the number of pairings of "additional" measures with at least one intervention from a main cluster group

\begin{tabular}{|c|c|c|c|c|}
\hline \multicolumn{5}{|l|}{ Workshop Seeds } \\
\hline 'Additional' & 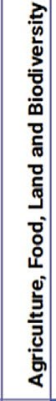 & 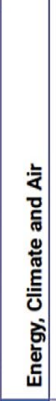 & 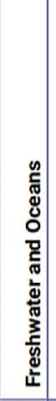 & 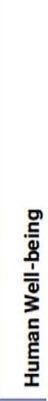 \\
\hline Monitoring and reporting & 2 & 5 & 0 & 1 \\
\hline Circular economy & 2 & 1 & 2 & 2 \\
\hline Sharing economy & 0 & 0 & 0 & 0 \\
\hline Plastics and consumer waste reduction & 2 & 1 & 0 & 2 \\
\hline Awareness and skills building & 1 & 3 & 0 & 0 \\
\hline Gender equality & 0 & 0 & 0 & 0 \\
\hline Smart cities for sustainability & 0 & 4 & 0 & 0 \\
\hline Ecosystem restoration & 0 & 0 & 1 & 0 \\
\hline Effective governance & 0 & 0 & 0 & 0 \\
\hline
\end{tabular}

building emerged as one of the strongest intervention categories and appeared in various proposals paired with all of the four main clusters. These CoLab proposals ranged in their suggestions from a mentoring network for women to female economic empowerment through activities like beekeeping. Agriculture, food, land and biodiversity emerged as the strongest cluster paired with various "other" interventions.

Of the nine additional interventions, two effective governance, and awareness and skills building were highlighted as important interventions across all six regional assessments. The regional assessments indicated the need to involve a diverse range of actors in seeking transformative solutions to achieve sustainable development, and all emphasized the need to develop new collaborations between business, government and civil society. In addition to these commonalities, the assessments strongly reflected region-specific issues.

In North America, the identified governance and capacity-building needs focused on integrated forward-looking approaches that leveraged new technologies and citizen science in monitoring and reporting that would ultimately internalize environmental costs in the economy. Africa and Latin America and the Caribbean emphasized effective implementation and regulation to prevent further habitat loss and land degradation, focusing strongly on policies that strengthen equitable land ownership and sustainable use of natural resources. Europe, and Asia and the Pacific strongly emphasized regional policy integration and cooperation. However, the outlook for Europe focused its policy coordination around encouraging sustainable lifestyles, while Asia and the Pacific emphasized coordination as an adaptation response in disaster risk reduction. In West Asia, the dominant governance issue was peace and security. Only three assessments (Africa, Europe, and Latin America and the Caribbean) emphasized the need for global governance in addressing tele-coupling aspects that transfer the impacts of production and consumption to other regions. This limited consideration of interregional impacts, particularly from major regions of consumption such as North America and parts of Asia and the Pacific, is concerning and we suggest should be included as an explicit criterion in future regional assessments.

While monitoring and reporting was a strongly represented measure in Seeds, it was far less prevalent in Climate CoLab proposals. In the regional assessments, it was emphasized by all regions except Europe, with a focus on the use of new technologies and citizen science to monitor future trends and report on sustainable development outcomes. Ecosystem restoration was also important in the regional assessments, but the focus differed in each region. In North America, restoration was considered important for improved water-quality management, while in West Asia restoration strongly focused on coastal marine ecosystems as a strategy to reduce disaster risk. In Europe, restoration was an integrative pathway to realizing multiple goals for biodiversity conservation, reinvigorating abandoned farmlands, reducing nitrogen and GHG emissions, and the mental and physical health benefits of restoring blue-green infrastructure.

Finally, there are clear indications from the bottom-up initiatives that circular economies and smart cities for sustainability represent emerging opportunities that can be leveraged as integrated and synergistic approaches to achieve 
sustainable futures. The contribution of the sharing and circular economies highlights innovations that boost the energy cluster, and also address production and consumption challenges in the agriculture, food, land and biodiversity cluster. These results also point to the richness of information provided by these bottom-up and participatory approaches that would not have been attained by traditional global assessments methods and associated scenarios.

\section{Commonalities across food and urban systems}

Based on the number of interventions that emerged from the bottom-up analysis, it became clear that the food system and urban systems were two very important areas for effecting transformative change. Here we describe cross-cutting interventions for sustainability from all three data collections in these two sub-systems.

\section{Food systems}

The food system is a key cross-cutting issue due to its wide-ranging environmental impacts (Gordon et al. 2017, Willett et al. 2019). A focus on food related interventions, therefore, emerged organically in the stakeholder engagement and crowdsourcing initiatives, in which 27 out of the 156 workshop-collected seeds and 11 out of the 34 Climate CoLab finalists' proposals related directly to food.

Several of the Seed workshops and CoLab proposals related to dietary change, specifically advocating increased uptake of and support for vegetarian and vegan diets. Such diets are widely understood to demand less land, water and energy than meat-based diets (Pimentel and Pimentel 2003), although regionally appropriate livestock rearing on pasture can be sustainable (Eisler et al. 2014). Others related to alternative farming methods (e.g. urban agriculture, rooftop farms, agroforestry) that could potentially have a positive impact on food security while reducing dependence on land and/or water resources. While the dominant focus of the Climate CoLab proposals was climate change, about onethird were still related to the food system. Proposed solutions ranged from broad-scope, global interventions such as a network of "tens of thousands of food forests" through to targeted interventions such as improving moisture-retention capacity of soils in drought-affected parts of Africa. The prominence of food in these bottom-up scenarios shows a clear willingness to embrace changes in the food system, suggesting a degree of public awareness of the necessity of change implied by top-down modelled scenarios.

Some of the proposed interventions represent gamechangers that potentially alter the way model-based foodproduction scenarios are developed. For example, modelled links between population, meat consumption, average agricultural yields and land use could be reimagined in light of widespread reuse of food waste for nutrient recovery (Cordell et al. 2011), while regenerative, ecological and multifunctional agriculture systems have the potential to both increase and diversify yields (Horlings and Marsden 2011). In addition, radical models of optimized hypothetical diets have also been presented in the literature (Ward et al. 2014), and could alter the conventional specification in top-down scenarios of a rigid relationship between humans and land use.

\section{Urban systems}

The participatory results focused to a large extent on improving urban environments, with SDG 11 (sustainable cities and communities) mentioned often, by $38 \%$ of all seeds workshop participants and half of all climate CoLab proposals. Analysis of these results also showed a variety of SDG synergies, supporting the idea of urbanization being a cross-cutting issue in which solutions can have multiple cobenefits. Seeds addressing SDG 11 had large synergies for addressing SDGs 3, 9, 12 and 13. Climate CoLab proposals also indicated several synergies with SDG 11, including for SDGs 3,12, 13 and 17. These coding results were further reflected in the descriptions of relevant Seeds and proposals, as many spoke of a variety of co-benefits for urban-based solutions.

Urban-related Seeds often focused on empowering citizens using online platforms and smartphone applications (apps). Some apps focused on allowing users to monitor and report their energy usage, air and water pollution, to identify plant species (biodiversity knowledge and awareness), and more. A core aspect of these apps was to enable data-based action in addition to educating users. An app to monitor energy consumption incorporated monetary incentives to change electricity use habits, and an app to monitor water quality connected directly to relevant municipal water agencies. Urban seeds also focused on infrastructure, particularly on developing green infrastructure through green roofs, community gardens and green building standards more generally.

In all four workshops, seeds-based visions often coalesced around sustainable cities or communities. Urban areas were imagined in which buildings are fitted with solar panels and/or green roofs, are built with sustainable materials, and make use of smart technologies to minimize energy usage. Pathways to sustainable futures often included setting aside spaces and providing infrastructure to enable urban agriculture, the products of which could be used for food as well as for sustainable consumer goods such as biodegradable or edible cutlery. One pathway focused specifically on an international cities platform that allows for environmental data and actions to be aggregated internationally, and to be used by citizens to learn and engage in sustainable community actions. 


\section{Linking interventions and bottom-up pathways to enabling conditions for transformative change}

The results presented above identify the nature of solutions needed, but these solutions do not necessarily imply transformative change. To achieve change at appropriate scale (local, region, nation), solutions need to be cognizant of and address the enabling and disruptive conditions that play a role in system transformations.

Sections 3.6.1. and 3.6.2. introduce categories of enabling and disruptive conditions for transformations based on a framework outlined by Kivimaa and Kern (2016). The categories are described in more detail with further examples from the literature, followed by references to the relevant workshop seeds and Climate CoLab proposals.

\section{Enabling conditions for creating innovation}

Establishing and supporting markets for innovations Governance for transformations should involve establishing and supporting new markets for innovations. This consists of policies like regulations, tax exemptions, deployment subsidies and labelling. For example, agroecological innovations and building markets for indigenous foods are being recognised as increasingly important for meeting food and nutrition security needs whilst improving the sustainability of the food system (Tomich et al. 2011; Akinola et al. 2020).

Some seeds and CoLab proposals mentioned creating and expanding markets such as an ethical fashion industry, and many others looked at innovations related to new and growing markets within the circular and sharing economies. Although there are strong arguments that a focus on a circular economy in the fashion industry risks addressing only material concerns and not taking into account the broader social-ecological system implications (Palm et al 2021). These changes may require market-supporting policies like the labelling of fashion projects that meet certain standards, and subsidies that make niche innovations (e.g. in reusing waste) more affordable for consumers. Policymakers and stakeholders should explore how more sustainable markets related to identified innovations can be supported until they become the norm.

\section{Supporting innovation experimentation and learn-} ing Learning and experimentation includes support for research and development, deployment and demonstration, policies that stimulate entrepreneurship, incubators, lowinterest loans, venture capital and supportive regulatory conditions. For example, national contexts for fostering innovation and technology uptake of rapidly emerging phenomenon such as pay-as-you-go digitally enabled business models in Africa that have had significant early success in providing poor people with access to technologies relevant to the sustainable development goals (SDGs) (e.g., for electricity access, water and sanitation, and agricultural irrigation) (Ockwell et al. 2019).

Not many seeds and CoLab proposals specifically addressed experimentation and learning support, although one Seed was an innovation lab focused on sustainable innovations at the local level.

Financial resource mobilization Financial resource support is the mobilization of financial capital through funding mechanisms, low-interest loans and venture capital. For example, improved information on climate change risks, reforms that recognize the value and benefits of long-term investment strategies, and financial reporting requirements on climate can all help enable increased private and public sector investments (Clark et al. 2018).

A large number of seeds and climate CoLab proposals identified a need for greater financial mobilization including the mobilization of domestic funds; the Inga Foundation's proposal seeks international funding, Govardhan Ecovillage proposes a Green Innovations Fund, and "Framework for Community-based Sustainable Development" mentions a need for developed countries to transfer financial resources (and technological expertise) to less developed countries (See Appendix 1). Some climate CoLab proposals were more in depth, calling for incentives for the elderly to work, incentives for developing carbon sinks, subsidies for organic farmers, and incentives/subsidies for individuals, cooperatives, and businesses supporting composting of urban solid waste.

Human resource mobilization Human resource support is the mobilization of human capital, e.g. through education and labour policies. For example, facilitating youth involvement in agriculture and providing skills and resources is important for achieving sustainable development (Metelerkamp et al. 2020).

Human resource mobilization was a salient theme within the seeds and CoLab proposals, particularly the role of educating and engaging people on environmental issues. There were a large number of awareness, knowledge, and skills development solutions, all of which help to mobilize people towards actioning transformations. Seeds-based visions from all workshops also listed public awareness as a key component of realizing the participants' imagined sustainable futures. Exciting examples of human resource mobilization included educating the youth to work on climate issues through the 'Youth Climate Leaders' and "Youth Informing Communities on Climate Change Adaptation through building homes" Climate CoLab proposals, and the many app-based solutions that make environmental engagement accessible. 


\section{Disruptive conditions to destabilise incumbents'}

Control policies and rules reform Control policies are taxes, trade restrictions and regulations that can be instituted by government actors to make existing processes less profitable or more sustainable. Rules reform consisting of radical policy reforms and changes in overarching rule structures. For example, control policies such as the EU emissions trading scheme help internalize environmental costs of carbon emissions and help level the playing field for niche innovations (Kivimaa and Kern 2016). It is important to acknowledge that transformations usually have winners and losers (Geels 2014). As such, for every new innovation there are displacements that can be promoted through control policies (and should be explored), although such policies should consider their wider implications as they can have unintended consequences.

Seeds and CoLab proposals related to control policies included introducing limits on plastic, reducing red meat from diets, and bans and taxes on plastic packaging. A few Seeds and CoLab proposals suggested entirely new rule structures to promote sustainability, such as embracing the concept of a wellbeing economy, lowering age requirements for voting for elected officials, introducing new financial systems that incorporate the value of the environment, and expanding the circular economy with extended producer responsibility.

Reduction in existing regime support The removal of supporting conditions that have allowed for the existing, problematic structures to be successful. For example, redirection of capital towards more sustainable practices: loan covenants, stock exchange listing rules, and shareholder activism could have profound impact on improving the sustainability of the seafood industry (Jouffray et al. 2019).

Solutions that tackled the conditions that make existing systems successful mostly focused on informing and engaging people on why the existing structures are problematic and how to do things differently. For example, many apps looked at education of users for how to improve their lifestyle to be environmentally friendly, and to promote programmes such as 'No Straw Tuesdays' aimed to challenge the excessive use of straws and plastics more broadly. Although there is significant potential in using finance to enable systemic change, no specific proposals along these lines were raised by participants, which reinforces the importance of having a wide range of expertise in participatory workshops.

Changes in networks and key actors The replacement of incumbent actors and the breaking of powerful actor-network structures in favour of new actors and networks more favourable to the desired transformations. For example, redefining social roles within communities and governance structures through novel forms of collective action, cooperatives, and associations; enabling new relationships that create space for grassroot initiatives and bottom-up solutions (Wolfram 2018).

Several seeds pathways and climate CoLab proposal finalists referenced changing current actor relations, specifically through building collaborative environments and new, involved networks of stakeholders. Decentralized power and action in large networks were key components of many Seeds. One climate CoLab proposal, 'C'SQUARE' reflected the trend found in Seeds pathways and mentioned the need to empower and mobilize citizens to gather their opinions to improve urban areas. Its success was dependent on strong partners and collaborations.

\section{Discussion}

\section{The contribution of bottom-up initiatives}

The lack of bottom-up futures in the context of global sustainability assessments poses major challenges. In terms of legitimacy, large-scale global or regional futures that do not represent the diversity of many different lived experiences, world views and discourses, risks giving insufficient space for the concerns and needs of different societal actors, and overlooking the social innovations these actors may have to offer (Pereira et al 2021). It is difficult to imagine transformative change if visions of large-scale sustainable futures do not draw on insights and perspectives from local and national actors, as well as incorporating diverse knowledge from indigenous people (IPBES 2019). Many of the Seeds for better futures exist today in the margins of current systems, which often means that they operate locally, even if they are sometimes organized through trans-local networks (Bennett et al. 2016). This applies also to Seeds that may contribute to more desirable futures, such as practices, technologies and forms of governance that might have a global impact. It also holds for new threats and risks that might modify the challenges of the anthropocene as they emerge, such as conflicts, natural resource crises, diseases and problematic technologies (Steffen et al. 2015). Furthermore, the lack of bottom-up contributions to global sustainability futures also has consequences for how these scenarios and visions are used. If global futures lack connections to on-theground realities, they may be deemed too theoretical and too generic to inform decision-making. The top-down framing of future challenges at local levels can limit what gets considered and affect the legitimacy of who contributes to this framing of the future (Vervoort et al. 2014).

Using bottom-up approaches, it can be possible to identify game-changing concepts that fundamentally restructure the way we view future scenarios. One tangible example is the 
development of small-scale, decentralized renewable energy systems. The rapid pace of technological development and the associated decrease in the cost of, among others, solar photovoltaics and battery storage, coupled with Internet and Communications Technology (ICT), makes microgrids a new possibility for areas not yet served by conventional electricity from fossil fuels. This has already become a reality in Kenya since the establishment of M-KOPA, a mobileenabled payment system for Solar Home Systems in 2013 (Ockwell et al. 2019). These technologies and the public demand to embrace them mean that the types of energy transition characterizing the past (coal to oil, oil to gas, gas to large-scale renewables) may not necessarily characterize the leapfrog development of energy supplies in the future (see Ockwell et al. 2018. for solar transition in Africa).

Another ongoing debate is on the need for enhanced assessment approaches that can cope with diverse evidence/knowledge systems, cross-scale interactions and the entanglement of facts and values at the international science-policy interface (Mach and Field 2017; Edenhofer and Minx, 2014; Jabbour et al. 2012), and still deliver, actionable information with purpose and credibility. The important contributions of bottom-up initiatives driven by different actors is thus increasingly recognized as core facets of a useful global assessment. For example, the Fifth Assessment Report of the IPCC acknowledged the role of local actors in global climate mitigation (Seto et al. 2014) and the UNEP Emissions Gap report found significant potential emission reductions by various non-state actors, complementing governments' commitments pledged in support of the Paris Agreement (UNEP 2019). National governments throughout the world have also begun to recognize that sound climate scenario modelling and assessment require contributions from bottom-up sources (Hsu et al. 2019). Individual actors frequently form hybrid coalitions, often in cooperation with national governments, building transnational climate governance networks, and demonstrate the potential additive effects of individual bottom-up climate actions when actors align goals and coordinate efforts (Andonova et al. 2009). The roles of different societal actors and diverse knowledge systems are made explicit in bottom-up approaches and they highlight the need for diverse higher-level enabling conditions like international agreements to enable niches (see Byrne et al. 2018).

In addition to making the role for diverse actors explicit, the results of this bottom-up approach have also highlighted geographical inequalities of where change needs to happen, emphasising a need for more equitable and equity-focussed interventions. The analysis of the Climate CoLab proposals, where an overwhelming focus was put on solutions for the global South, particularly countries in Africa and Asia, highlights existing inequities in the perceptions of where interventions are necessary for transformation, and of who needs to act (Parks and Roberts 2008; Newell 2015; Nagendra et al. 2018). This imbalance can obscure or ignore the role of the global North in current development trajectories (e.g. focusing only on poverty alleviation and not discussing wealth redistribution). While the GEO Regional Assessment for Europe (UNEP 2016e) did highlight trade-offs and tensions associated with tele-coupling (e.g. highlighting consumption patterns in one region driving environmental concerns related to production in another region) (See examples from Adger et al. 2009; Liu et al. 2013; Seaquist et al. 2014), the limited emphasis on such cross-scale impacts is of concern and requires concerted research effort. Here, incorporating principles of distributive justice-normative principles designed to guide the allocation of the benefits and burdens of economic activity based on fair distribution (Lamont and Favor 2008) can help to construct a development agenda based on principles of equity and equality and further efforts towards SDG 10 of reducing inequalities. An equity-based approach can provide options for where and how to implement solutions with the most transformative potential to achieve just and sustainable development; for example, in reforming consumption and production patterns or in instituting market mechanisms such as caps on trade, carbon taxes and offsetting schemes.

Many of the solutions presented in this paper offer opportunities for countries in the global South to leapfrog onto more sustainable and equitable development trajectories through pathways that link diverse SDGs. For example, the use of ICT plays a major role in driving change in the bottom-up pathways in food, water and energy systems, and sustainable cities, and indicates tangible solutions for how these more sustainable and equitable change processes are facilitated. There are already many good examples of how this is being leveraged for change in the global South (Karpouzoglou et al. 2017; Ockwell et al. 2018). Finally, the economics of transformative change for sustainability have become important research discussions as the degrowth movement and other eco-socialist concepts are becoming increasingly influential (Hickel 2019; Otero et al. 2020; D'Alessandro et al. 2020). This economic shift was also captured by the many initiatives for sharing and circular economies in the bottom-up pathways that could help enable a transformative shift to a well-being economy.

\section{Next steps for integrating a bottom-up approach into global environmental assessment scenarios}

The analysis presented in this paper offers new insights on how contemporary global environmental assessments and their socially constructed processes can be adapted to facilitate more inclusive and contextualized explorations of futures amidst the increasingly complex interrelationships 
between decision-making, knowledge, and society. This paper has demonstrated the potential of including bottomup approaches in GEAs; however, more work is needed to implement such findings in global decision-making and/or model-based future scenarios that inform national and multinational policies. As indicated by the "additional interventions" for achieving the SDGs that stem from bottom-up, participatory approaches, which are not captured by the measures suggested in global IAMs, there is a clear knowledge gap in current IAM-dominated approaches for decision-making about more sustainable futures. To address this, more comprehensive participatory approaches are needed to capture the crucial aspects that cannot be captured by the IAMs, and hence identify further knowledge gaps that are relevant for decision-making.

The process pioneered in GEO-6 represents an opportunity, if refined and adopted in future assessments, for the top-down scenario-development community to receive feedback on the public acceptance of the various interventions and their trade-offs adopted through bottom-up approaches. To meet the requirement of an increased food supply, for example, pathways include the expansion of agricultural land for rain-fed agriculture (at the expense of biodiversity), or increased use of fertilizer and irrigation to improve yields on the land already in use (at the expense of water resources and pollution). Stakeholders could be consulted to gain insights into the relative acceptance of different options, as well as to identify blind spots in the modelling approach that may mean alternative, synergistic solutions are being overlooked. Similarly, gaps in actual interventions that could help to achieve SDGs targets can also be revealed as is the case with interventions specifically aimed at drivers like population growth and anthropogenic climate change that present an important challenge to sustainability, as identified across the GEO-6 report (UNEP 2019).

Longer-term possibilities for integration could include quantitative aggregation of local scenarios and Seed initiatives with direct links to model inputs and outputs; and model integration with online crowdsourcing of bottom-up pathways. However, while GEO-6 demonstrated the potential benefits of such two-way integration, there remain significant challenges before it can become routinely included in practice. This stems from the fact that the methodologies currently employed in exploring local or seed initiatives tend not to result in these scenarios being described in quantitative terms, or with system linkages sufficiently articulated to enable their incorporation in IAMs. We contend that this may be overcome by developing explicit cross-disciplinary methodologies with integration in mind. The challenge for the research community is to achieve the quantitative rigour required of modeling, without sacrificing the participatory benefits of bottom-up scenario creation (Pereira et al 2021).

\section{Concluding remarks}

Our analysis of potential bottom-up and regional solutions for sustainability has highlighted that there is an important contribution that bottom-up approaches can make to global environmental assessments. We show that by including bottom-up activities, a more accurate understanding of both existing sustainability interventions and knowledge gaps can be identified. Moreover, the inclusion of bottomup activities can help national governments to support and account for bottom-up activities in their own agenda setting and ensure the relevance to their needs. For instance, by identifying small-scale initiatives that provide functions (e.g. capacity-building or piloting of innovative solutions) that may be difficult to quantify, but can be critical to achieving the transition to a more sustainable society (Chan et al. 2016), a wider space for policy interventions could be opened up. The concentration of activities in the global South further suggests that noting these activities could fill a key data gap in current records of sustainability innovations occurring beyond the global North. However, it also points to an interesting global discourse that may be emphasising that the regions where change needs to occur are in the South, rather than addressing patterns of resource over-consumption in the North. Overall, as an experimental intervention to gain bottom-up insights for the GEO-6 report, the process outlined in this paper demonstrates the potential for future assessments to take some of these approaches on board in order to situate their findings more readily in what is already happening on the ground, and to make the outcome of GEAs more useful and actionable for decision makers and practitioners.

Supplementary Information The online version contains supplementary material available at https://doi.org/10.1007/s11625-021-01013-x.

Acknowledgements This work is based on the research supported in part by the National Research Foundation of South Africa (Grant Number 115300), and the Swedish Research Council FORMAS Project Nos 2018-02371 and 2020-00670. The authors would like to acknowledge funding from the CGIAR Research Program on Climate Change, Agriculture and Food Security (CCAFS), which is carried out with support from the CGIAR Trust Fund and through bilateral funding agreements (see https://ccafs.cgiar.org/donors); as well as funding from the Programme on Climate Smart Livestock at ILRI, which was commissioned by GIZ and funded by the Government of the Federal Republic of Germany. The views expressed in this document cannot be taken to reflect the official positions of these organisations.

Funding Open access funding provided by Stockholm University.

Open Access This article is licensed under a Creative Commons Attribution 4.0 International License, which permits use, sharing, adaptation, distribution and reproduction in any medium or format, as long as you give appropriate credit to the original author(s) and the source, provide a link to the Creative Commons licence, and indicate if changes were made. The images or other third party material in this article are 
included in the article's Creative Commons licence, unless indicated otherwise in a credit line to the material. If material is not included in the article's Creative Commons licence and your intended use is not permitted by statutory regulation or exceeds the permitted use, you will need to obtain permission directly from the copyright holder. To view a copy of this licence, visit http://creativecommons.org/licenses/by/4.0/.

\section{References}

Abbott KW (2012) The transnational regime complex for climate change. Environ Plan C Gov Policy 30:571-590. https://doi.org/ $10.1068 / \mathrm{c} 11127$

Adger WN, Eakin H, Winkels A et al (2009) Nested and teleconnected vulnerabilities to environmental change. Front Ecol Environ 7:150-157. https://doi.org/10.1890/070148

Aguiar APD, Collste D, Harmáčková Zv et al (2020) Co-designing global target-seeking scenarios: a cross-scale participatory process for capturing multiple perspectives on pathways to sustainability. Glob Environ Change 65. https://doi.org/10.1016/j.gloen vcha.2020.102198

Akinola R, Pereira LM, Mabhaudhi T (2020) A review of indigenous food crops in africa and the implications for more sustainable and healthy food systems. Sustainability 12:3493. https://doi.org/10. 3390/su12083493

Andonova LB, Betsill MM, Bulkeley H (2009) Transnational climate governance. Glob Environ Polit 9:52-73. https://doi.org/10.1162/ glep.2009.9.2.52

Bennett E, Carpenter S, Peterson G et al (2003) Why global scenarios need ecology. Front Ecol Environ 1:322-329. https://doi.org/10. 1890/1540-9295(2003)001[0322:WGSNE]2.0.CO;2

Bennett EM, Solan M, Biggs R et al (2016) Bright spots: seeds of a good anthropocene. Front Ecol Environ 14:441-448. https://doi. org/10.1002/fee.1309

Biggs R, Westley FR, Carpenter SR et al (2015) The Anthropocene: from global change to planetary stewardship. Anthr Rev 40:739761. https://doi.org/10.1007/s13280-011-0185-x

Byrne R, Mbeva K, Ockwell D (2018) A political economy of nichebuilding: Neoliberal-developmental encounters in photovoltaic electrification in Kenya. Energy Res Soc Sci 44:6-16. https://doi. org/10.1016/j.erss.2018.03.028

Calvin K, Patel P, Clarke L et al (2019) GCAM v5.1: representing the linkages between energy, water, land, climate, and economic systems. Geosci Model Dev 12:677-698. https://doi.org/10.5194/ gmd-12-677-2019

Castree N, Bellamy R, Osaka S (2020) The future of global environmental assessments: making a case for fundamental change. The Anthropocene Rev. https://doi.org/10.1177/2053019620971664

Chan S, Brandi C, Bauer S (2016) Aligning transnational climate action with international climate governance: the road from Paris. Rev Eur Comp Int Environ Law 25:238-247. https://doi.org/10.1111/ reel.12168

Chapman SE, Birch C, Pope E et al (2020) Impact of climate change on crop suitability in sub-Saharan Africa in parameterized and convection-permitting regional climate models. Environ Res Lett15:94086. https://doi.org/10.1088/1748-9326/ab9daf

Chen H, Matsuhashi K, Takahashi K et al (2020) Adapting global shared socio-economic pathways for national scenarios in Japan. Sustain Sci 15:985-1000. https://doi.org/10.1007/ s11625-019-00780-y

Clark R, Reed J, Sunderland T (2018) Bridging funding gaps for climate and sustainable development: pitfalls, progress and potential of private finance. Land Use Policy 71:335-346. https://doi.org/ 10.1016/j.landusepol.2017.12.013
Cordell D, Rosemarin A, Schröder JJ, Smit AL (2011) Towards global phosphorus security: a systems framework for phosphorus recovery and reuse options. Chemosphere 84:747-758. https://doi.org/ 10.1016/j.chemosphere.2011.02.032

D’Alessandro S, Cieplinski A, Distefano T, Dittmer K (2020) Feasible alternatives to green growth. Nat Sustain. https://doi.org/10.1038/ s41893-020-0484-y

Edenhofer O, Minx J (2014) Mapmakers and navigators, facts and values. Science 345(6192):37-38

Eisler MC, Lee MRF, Tarlton JF, Martin GB (2014) Steps to sustainable livestock. Nature 507:32-34. https://doi.org/10.1038/507032a

Elmqvist T, Bai X, Frantzeskaki N et al (2018) Urban Planet. Cambridge University Press, Cambridge

Geels FW (2014) Regime resistance against low carbon transitions: introducing politics and power into the multi-level perspective. Theory Cult Soc 31:21-40. https://doi.org/10.1177/0263276414 531627

Ghisellini P, Cialani C, Ulgiati S (2016) A review on circular economy: the expected transition to a balanced interplay of environmental and economic systems. J Clean Prod 114:11-32. https://doi.org/ 10.1016/j.jclepro.2015.09.007

Gollwitzer L, Ockwell D, Muok B et al (2018) Rethinking the sustainability and institutional governance of electricity access and mini-grids: electricity as a common pool resource. Energy Res Soc Sci 39:152-161. https://doi.org/10.1016/j.erss.2017.10.033

Gordon LJ, Bignet V, Crona B et al (2017) Rewiring food systems to enhance human health and biosphere stewardship. Environ ResLett 12. https://doi.org/10.1088/1748-9326/aa81dc

Hamari J, Sjöklint M, Ukkonen A (2016) The sharing economy: why people participate in collaborative consumption. J Assoc Inf Sci Technol 67:2047-2059. https://doi.org/10.1002/asi.23552

Hebinck A, Vervoort JM, Hebinck P etal (2018) Imagining transformative futures: participatory foresight for food systems change. Ecol Soc 23.https://doi.org/10.5751/ES-10054-230216

Hickel J (2019) Is it possible to achieve a good life for all within planetary boundaries? Third World q 40(1):18-35

Hölscher K, Frantzeskaki N (2020)Transformative climate governance: a capacities perspective to systematise. Eval Guide Climate Action

Horlings LG, Marsden TK (2011) Towards the real green revolution? exploring the conceptual dimensions of a new ecological modernisation of agriculture that could 'feed the world.' Glob Environ Chang 21:441-452. https://doi.org/10.1016/j.gloenvcha.2011.01. 004

Hsu A, Höhne N, Kuramochi T et al (2019) A research roadmap for quantifying non-state and subnational climate mitigation action. Nat Clim Chang 9:11-17. https://doi.org/10.1038/ s41558-018-0338-z

IPBES (2019) The global assessment report on biodiversity and ecosystem services of the intergovernmental science-policy platform on biodiversity and ecosystem services. Bonn, Germany

Jabbour J, Flachsland C (2017) 40 years of global environmental assessments: a retrospective analysis. Environ Sci Policy 77:193202. https://doi.org/10.1016/J.ENVSCI.2017.05.001

Jabbour J, Keita-Ouane F, Hunsberger C, Sánchez-Rodríguez R, Gilruth P, Patel N, Singh A, Levy MA, Schwarzer S (2012) Internationally agreed environmental goals: a critical evaluation of progress? Environ Dev 3(2):5-24

Jiménez-Aceituno A, Peterson GD, Norström AV et al (2019) Local lens for SDG implementation: lessons from bottom-up approaches in Africa. Sustain Sci 15:729-743. https://doi.org/10.1007/ s11625-019-00746-0

Jouffray J-B, Crona B, Wassénius E et al (2019) Leverage points in the financial sector for seafood sustainability. Sci Adv. https://doi.org/ 10.1126/sciadv.aax3324 
Karpouzoglou T, Pereira LM, Doshi S (2017) Bridging ICTs with governance capabilities for food-energy-water sustainability. In: Pereira LM, McElroy C, Littaye A, Girard AM (eds) Food, energy and water sustainability: emergent governance strategies. Earthscan, Oxford, UK, pp 222-238

Kenward R, Papathanasiou J, Manos B, Arampatzis E (2013) Transactional environmental support system design:global solutions. IGI Global, Hershey, PA

Kivimaa P, Kern F (2016) Creative destruction or mere niche support? Innovation policy mixes for sustainability transitions. Res Policy 45:205-217. https://doi.org/10.1016/j.respol.2015.09.008

Kowarsch M, Jabbour J, Flachsland C et al (2017) A road map for global environmental assessments. Nat Clim Chang 7:379

Kuramochi T, Roelfsema M, Hsu A et al (2020) Beyond national climate action: the impact of region, city, and business commitments on global greenhouse gas emissions. Clim Policy 20:275-291. https://doi.org/10.1080/14693062.2020.1740150

Lamont J, Favor C (2008) Distributive justice. In: Zalta E (ed) Stanford encyclopedia of philosophy. Stanford University Press, Stanford

Liu J, Hull V, Batistella M et al (2013) Framing Sustainability in a Telecoupled World. Ecol Soc. https://doi.org/10.5751/ ES-05873-180226

Mach KJ, Field CB (2017) Toward the next generation of assessment. Annu Rev Environ Resour 42:569-597

Malone TW, Nickerson J V., Laubacher RJ, et al (2017) Putting the Pieces Back Together Again. In: Proceedings of the 2017 ACM Conference on Computer Supported Cooperative Work and Social Computing. Portland, USA, pp 1661-1674

Mason-D'Croz D, Vervoort J, Palazzo A et al (2016) Multi-factor, multi-state, multi-model scenarios: exploring food and climate futures for Southeast Asia. Environ Model Softw 83:255-270. https://doi.org/10.1016/J.ENVSOFT.2016.05.008

Merrie A, Keys P, Metian M, Österblom H (2018) Radical ocean futures-scenario development using science fiction prototyping. Futures 95:22-32. https://doi.org/10.1016/J.FUTURES. 2017.09.005

Metelerkamp L, Biggs R, Drimie S (2020) Learning for transitions: a niche perspective. Ecol Soc. https://doi.org/10.5751/ es-11326-250114

Moore ML, Tjornbo O, Enfors E et al (2014) Studying the complexity of change: toward an analytical framework for understanding deliberate social-ecological transformations. Ecol Soc. https:// doi.org/10.5751/ES-06966-190454

Moore M-L, Riddell D, Vocisano D (2015) Scaling out, scaling up, scaling deep: strategies of non-profits in advancing systemic social innovation. J Corp Citizsh 58:67-84

Nagendra H, Bai X, Brondizio ES, Lwasa S (2018) The urban south and the predicament of global sustainability. Nat Sustain 1:341349. https://doi.org/10.1038/s41893-018-0101-5

Neumann K, Verburg PH, Stehfest E, Müller C (2010) The yield gap of global grain production: A spatial analysis. Agric Syst 103:316326.https://doi.org/10.1016/j.agsy.2010.02.004

Newell P (2015) The Politics of Green Transformations in Capitalism. In: Scoones I, Leach M, Newel P (eds) The politics of green transformation. Earthscan, London

Ockwell D, Byrne R, Hansen UE et al (2018) The uptake and diffusion of solar power in Africa: socio-cultural and political insights on a rapidly emerging socio-technical transition. Energy Res Soc Sci 44:122-129. https://doi.org/10.1016/j.erss. 2018.04.033

Ockwell D, Atela J, Mbeva K et al (2019) Can Pay-As-You-Go, digitally enabled business models support sustainability transformations in developing countries? outstanding questions and a theoretical basis for future research. Sustainability 11:2105. https:// doi.org/10.3390/su11072105
Olsson P, Gunderson LH, Carpenter SR et al (2006) Shooting the rapids: navigating transitions to adaptive governance of social-ecological systems. Ecol Soc. https://doi.org/10.5751/ ES-01595-110118

Otero I, Farrell KN, Puello S et al (2020) Biodiversity policy beyond economic growth. Conserv Lett. https://doi.org/10.1111/conl. 12713

Palazzo A, Vervoort JM, Mason-D'Croz D et al (2017) Linking regional stakeholder scenarios and shared socioeconomic pathways: quantified West African food and climate futures in a global context. Glob Environ Change 45:227-242. https://doi.org/10. 1016/j.gloenvcha.2016.12.002

Palm C, Cornell S, Häyhä T (2021) Making resilient decisions for sustainable circularity of fashion. Circ, EconSust. https://doi.org/ 10.1007/s43615-021-00040-1

Parks BC, Roberts JT (2008) Inequality and the global climate regime: breaking the north-south impasse. Cambridge Rev Int Aff 21:621648. https://doi.org/10.1080/09557570802452979

PBL (2012) Roads from Rio+20: pathways to achieve global sustainability goals by 2050. PBL Netherlands Environmental Assessment Agency, Den Haag, The Netherlands

Pereira LM, Hichert T, Hamann M et al (2018) Using futures methods to create transformative spaces: visions of a good anthropocene in southern Africa. Ecol Soc. https://doi.org/10.5751/ ES-09907-230119

Pereira L, Kuiper JJ, Selomane O, Ana Paula D, Aguiar GR, Asrar EM, Bennett RB, Calvin K, Hedden S, Hsu A, Jabbour J, King N, Köberle AC, Lucas P, Nel J, Norström AV, Peterson G, Sitas N, Trisos C, van Vuuren DP, Vervoort J, Ward J (2021) Advancing a toolkit of diverse futures approaches for global environmental assessments. Ecosyst People. https://doi.org/10.1080/26395916. 2021.1901783

Pereira L, Asrar GR, Fisher LH et al (2019) Bottom-up initiatives and participatory approaches for outlooks. In: Global Environment Outlook (GEO 6). Cambridge University Press, Cambridge

Pimentel D, Pimentel M (2003) Sustainability of meat-based and plantbased diets and the environment. Am J Clin Nutr 78:660-663. https://doi.org/10.1093/ajcn/78.3.660s

Rosa IMD, Pereira HM, Ferrier S et al (2017) Multiscale scenarios for nature futures. Nat Ecol Evol 1:1416-1419. https://doi.org/ 10.1038/s41559-017-0273-9

Seaquist JW, Johansson EL, Nicholas KA (2014) Architecture of the global land acquisition system: applying the tools of network science to identify key vulnerabilities. Environ Res Lett. https://doi. org/10.1088/1748-9326/9/11/114006

Seto KC, Dhakal S, Bigio A et al (2014) Human settlements, infrastructure and spatial planning. In: Edenhofer O, Pichs-Madruga R, Sokona Y et al (eds) Climate Change 2014: Mitigation of Climate Change. Contribution of Working Group III to the Fifth Assessment Report of the Intergovernmental Panel on Climate Change. Cambridge University Press, Cambridge and New York

Sharpe B, Hodgson A, Leicester G et al (2016) Three horizons: a pathways practice for transformation. Ecol Soc. https://doi.org/ 10.5751/ES-08388-210247

Steffen W, Richardson K, Rockström J et al (2015) Planetary boundaries: guiding human development on a changing planet. Science 348:1217. https://doi.org/10.1126/science.aaa9629

Tomich TP, Brodt S, Ferris H et al (2011) Agroecology: a review from a global-change perspective. Annu Rev Environ Resour 36:193222. https://doi.org/10.1146/annurev-environ-012110-121302

UNEP (2016a) GEO-6 Regional Assessment for Africa. Nairobi, Kenya

UNEP (2016b) GEO-6 Regional Assessment for West Asia. Nairobi, Kenya

UNEP (2016c) GEO-6 Regional Assessment for North America. Nairobi, Kenya 
UNEP (2016d) GEO-6 Regional Assessment for Latin America and the Caribbean. Nairobi, Kenya

UNEP (2016e) GEO-6 Regional Assessment for Europe. Nairobi, Kenya

UNEP (2016f) GEO-6 Regional Assessment for Asia and the Pacific. Nairobi, Kenya

UNEP (2017a) Second GEO-6 Innovative Scenarios and Policy Pathways Stakeholder Visioning Workshop. Nansha, Nairobi, Kenya

UNEP (2017b) Third GEO-6 Innovative Scenarios and Policy Pathways Stakeholder Visioning Workshop: Nairobi. Nairobi, Kenya

UNEP (2017c) First GEO-6 Innovative Scenarios and Policy Pathways Stakeholder Visioning Workshop. Nairobi, Kenya, Bangkok

UNEP (2018) Fourth GEO-6 Innovative Scenarios and Policy Pathways Stakeholder Visioning Workshop. Singapore, Nairobi, Kenya

UNEP (2019) Global Environmental Outlook (GEO-6): Healthy Planet. Cambridge University Press, Cambridge, U.K, Healthy People

United Nations (2015) Transforming our world: the 2030 Agenda for Sustainable Development. United Nations Department of Economic and social affairs, New York

United Nations Environment Programme (2019) Emissions Gap Report. UNEP, Nairobi, Kenya

Van Vuuren DP, Kok MTJ, Girod B et al (2012) Scenarios in global environmental assessments: key characteristics and lessons for future use. Glob Environ Chang 22:884-895

Vervoort JM, Thornton PK, Kristjanson P et al (2014) Challenges to scenario-guided adaptive action on food security under climate change. Glob Environ Chang 28:383-394. https://doi.org/10. 1016/j.gloenvcha.2014.03.001

van Vuuren D, Lucas P, Calvin K et al (2019) Chapter 22 pathways towards sustainable development global environment outlook (GEO 6). Cambridge University Press, Cambridge

Ward JD, Ward PJ, Mantzioris E, Saint C (2014) Optimising diet decisions and urban agriculture using linear programming. Food Secur 6:701-718. https://doi.org/10.1007/s12571-014-0374-0

Willett W, Rockström J, Loken B et al (2019) Food in the anthropocene:the EAT-lancet commission on healthy diets from sustainable food systems. Lancet 6736:3-49.https://doi.org/10. 1016/S0140-6736(18)31788-4

Wolfram M (2018) Cities shaping grassroots niches for sustainability transitions: conceptual reflections and an exploratory case study. J Clean Prod 173:11-23. https://doi.org/10.1016/j.jclepro.2016. 08.044

Zurek MB, Henrichs T (2007) Linking scenarios across geographical scales in international environmental assessments. Technol Forecast Soc Change 74:1282-1295. https://doi.org/10.1016/j. techfore.2006.11.005

Publisher's Note Springer Nature remains neutral with regard to jurisdictional claims in published maps and institutional affiliations.

\section{Authors and Affiliations}

\section{Laura Pereira 1,2,3,4 . Ghassem R. Asrar ${ }^{5} \cdot$ Rohan Bhargava $^{3,6} \cdot$ Laur Hesse Fisher $^{7} \cdot$ Angel Hsu $^{8}$. Jason Jabbour ${ }^{9,10}$. Jeanne $\mathrm{Nel}^{11}$. Odirilwe Selomane ${ }^{1} \cdot$ Nadia Sitas $^{1,12} \cdot$ Christopher Trisos $^{13} \cdot$ James Ward $^{14} \cdot$ Mandy van den Ende $^{3}$. Joost Vervoort ${ }^{3} \cdot$ Amy Weinfurter $^{7}$}

1 Centre for Sustainability Transitions, Stellenbosch University, Stellenbosch, South Africa

2 Global Change Institute, University of the Witwatersrand, Johannesburg, South Africa

3 Copernicus Institute of Sustainable Development, Utrecht University, Utrecht, The Netherlands

4 Stockholm Resilience Centre, Stockholm, Sweden

5 Universities Space Research Association, Maryland, USA

6 Urban Systems Lab, New School, New York, USA

7 Environmental Solutions Initiative, Massachusetts Institute of Technology, Cambridge, MA, USA
8 Department of Public Policy, University of North Carolina-Chapel Hill, North Carolina, United States

9 Technischen Universität Berlin, Berlin, Germany

10 United Nations Environment Programme, Washington, D.C., USA

11 Nelson Mandela University, Gqeberha, South Africa

12 Department of Conservation Ecology, Stellenbosch University, Stellenbosch, South Africa

13 African Climate and Development Initiative, University of Cape Town, Cape Town, South Africa

14 University of South Australia, Adelaide, Australia 